\title{
Influence of Mucor mucedo immobilized to corncob in remediation of pyrene contaminated agricultural soil
}

\author{
Hou Wei ${ }^{1}$, Zhang Le ${ }^{1}$, Li Xiaojun ${ }^{+}$, Gong Zongqiang ${ }^{2}$, Yang Yongwei ${ }^{1}$, Li Zhi ${ }^{1}$ \\ ${ }^{1}$ College of Environmental Science, Liaoning University, Shenyang 110036, China \\ ${ }^{2}$ Key Laboratory of Pollution Ecology and Environmental Engineering, Institute of Applied Ecology, Chinese Academy of Sciences, Shenyang 110016, China
}

\begin{abstract}
In recent years, immobilization agents were introduced into organic contaminated soil remediation and more and more materials were screened and used as the immobilizing carrier. However, effect of the decomposition of the immobilizing carrier on the bioremediation was rarely concerned. Therefore, the decomposition experiment of immobilizing carrier -corncob was carried out in the lab with the efficient degradation fungi Mucor mucedo (MU) existing, and polycyclic aromatic hydrocarbons (PAHs) residues E4/E6 of the dissolved organic matter and microbial diversity during the decomposition process were studied. The results showed that: a) during the decomposition, the degradation of pyrene (Pyr) was mainly in the first $28 \mathrm{~d}$ in which the content of extractable Pyr decreased rapidly and the highest decrease was in the treatment with only MU added. b) Anslysis of E4/E6 changes showed that rich microorganisms could promote aromatization and condensation of humus. c) From the diversity index analysis it can also be seen that there is no significant difference in effects of PAHs on the uniformity of microorganisms. These results will not only be useful to have a better understanding of the bioavailability of contaminants adsorbed to biodegradable carriers in PAHs contaminated soil remediation, but also be helpful to perfect the principle of immobilized microbial technique.
\end{abstract}

Keywords: Immobilizing carrier, Microbial diversity, Mucor mucedo (MU), Polycyclic aromatic hydrocarbons (PAHs) degradation

\section{Introduction}

Polycyclic aromatic hydrocarbons (PAHs) contamination has become a common soil pollution type and has been highly concerned as the contamination degree exacerbating. The magnitude of pollution levels has increased from $\mu \mathrm{g} / \mathrm{kg}$ to $\mathrm{mg} / \mathrm{kg}$ and the detection rate has risen to more than $80 \%$ from less than $20 \%$. In addition, approximately $20 \%$ of major agricultural products content of PAHs exceeds the standard [1]. PAHs contamination will result in degradation of soil function and reduction of agricultural production. More importantly, through food chain or food web contaminants will be taken into and accumulated in human body, which endanger human health potentially. A large number of studies showed that PAHs content taken into human body through soil was greater than that through water and atmosphere [2]. Therefore, remediation of PAHs contaminated soil has become the important research subject. The microbial remediation technique has become a continuous concern for its low cost, high efficiency and environmental responsibility [3, 4]. In addition, introduction of immobilization agents to PAHs contaminated soil remediation has made some achievements in immobilizing carrier screening and processing etc., which is gradually shifting from experimental research and development to field application [5-7]. Therefore, how to screen high efficient degrading bacteria is the key to efficient application of microbial remediation technology. According to Wang et al. [8], three strains through separate and mixed immobilization, respectively, were used to degrade pyrene and benzo[a]pyrene $(\mathrm{B}[a] \mathrm{P})$ in soil. The results showed that the degradation efficiency of immobilized microorganism was much better than that of free bacteria and compared with separate immobilization, the degradation efficiency was generally higher through mixed immobilization. Li et al. [9] studied phenanthrene and pyrene in soil based on the immobilized microbial technique (IMT) and Li believed that IMT was helpful to enhance the competitiveness of introduced microorganisms in soil and was an effective method for the degradation of PAHs in soil. Gentili et al. [10] immobilized Rhodococcus corynebacterioides to chitin and chitosan to repair oil polluted seawater and the results showed that compared with separate free bacteria treatment, the removal rate of contaminants by immobilized bacteria was increased by approximately $30 \%$. Researches also showed that Phanerochaetechrysosporium immobilized by bagasse could greatly enhance the activity of manganese peroxidase and the
This is an Open Access article distributed under the terms of the Creative Commons Attribution Non-Commercial License (http://creativecommons. org/ licenses/by-nc/3.0/) which permits unrestricted non-commercial use, distribution, and reproduction in any medium, provided the original work is properly cited.
Received January 30, 2015 Accepted April 1, 2015

$\uparrow$ Corresponding author Email: boblxlucky@163.com Tel: +86-130-7247-0592 Fax: +86-24-6220-2248

Copyright (C) 2015 Korean Society of Environmental Engineers 
removal rate of anthracene in water [11]. By immobilizing Mucor sp. to corncob in order to repair B $[a] \mathrm{P}$ contaminated soil, Su et al. [12] found that immobilized Mucor sp. had a better environmental resilience and a faster reaction speed, obviously resulting in a higher removal rate of $\mathrm{B}[a] \mathrm{P}$. According to Dzul-puc et al. [13], in order to repair $\mathrm{B}[a] \mathrm{P}$ contaminated soil Phanerochaete chrysosporium was immobilized to pine needle powder and bagasse, respectively, and found that the $\mathrm{B}[a] \mathrm{P}$ degradation rate was faster when bagasse was taken as immobilizing carrier. Bacteria could also be immobilized to plant residues, which could enhance removal rate of PAHs by immobilized bacteria and indigenous microorganisms to a certain extent [14-16].

Therefore, in this paper the decomposition process of immobilizing carrier (organic material) was simulated in laboratory in order to study the effects of high efficient degrading bacteria on the decomposition process of immobilizing carrier and microbial diversity changes, so as to provide theoretical support for revealing the influence mechanism of immobilizing carrier in degradation of contaminants in soil.

\section{Materials and Methods}

\subsection{Materials}

Corncob was collected from the Shenyang ecological Experimental Station, Chinese Academy of Sciences, in the Liaoning province of

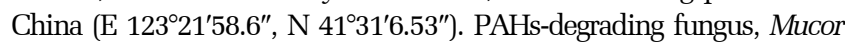
mucedo (MU) which had been successfully applied to remediation of contaminated soil of farmland in Shenfu sewage irrigated area (SIA, southeast of Shenyang, Liaoning province, China) were screened from heavily contaminated soil of SIA using the method of enrichment and culture in a mineral plate where PAHs were added as sole carbon and energy source and cultured according to the study of $\mathrm{Li}$ et al. $[17,18]$; Pyrene (Pyr) was purchased from sigma cooperation with purity of 98\%; Contaminated soil was collected from topsoil (0-20 $\mathrm{cm}$ ) of long-term contaminated farmland in upstream of Shenfu irrigated area and fresh soil was stored at $4^{\circ} \mathrm{C}$.

\subsection{Experimental Methods}

\subsubsection{Corncob pretreatment}

The dried corncobs were crushed to particles with diameter 0.6-0.8 $\mathrm{mm}$ and were pretreated by soaking in calcium hydroxide for $24 \mathrm{~h}$ and then mixed with other accessories in the proportion of the formula [18] and stirred to constitute the microorganism immobilizing carrier. The water content of the carrier mixture was maintained between $30-50 \%$, while $\mathrm{pH}$ was adjusted to 7.0 with $\mathrm{Ca}(\mathrm{OH})_{2}$ solution. The carrier mixture was then sterilized by autoclaving twice at $121^{\circ} \mathrm{C}, 1 \times 10^{5}$ pa for $90 \mathrm{~m}$.

\subsubsection{Soil solution}

$100 \mathrm{~g}$ pre-activated field soil (wet) was mixed with $500 \mathrm{ml}$ sterilized distilled water. The mixture was shaken on a reciprocal shaker (175 rpm) for $3 \mathrm{~h}$ then stand $16 \mathrm{~h}$ to clarify soil solution. The aqueous suspensions (soil solution) were used in the following experiment. The pre treatment of the field soil meant culture the field soil at $28^{\circ} \mathrm{C}$ for $3-5$ days to activate the microbial populations in soil in which the water content was kept in $20-30 \%(\mathrm{~W} / \mathrm{W})$.

\subsubsection{Inoculated fungi}

MU stored in laboratory was inoculated into potato liquid nutrient

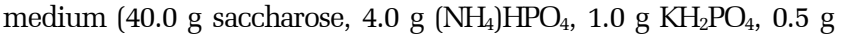
$\mathrm{MgSO}_{4} \cdot 7 \mathrm{H}_{2} \mathrm{O}$ and $0.05 \mathrm{~g}$ vitamin $\mathrm{B} 1$ per $\mathrm{L}$ ) and then was cultured for 3 days in an incubator at $28^{\circ} \mathrm{C}$.

\subsubsection{Experimental design}

The target PAHs, pyrene, was dissolved in high performance liquid chromatography (HPLC) grade acetone and kept at $-20^{\circ} \mathrm{C}$ until required. According to the Table 1, the treatments were prepared in the sterile room. The pre-treated corncobs, soil solution, pyrene and MU were added and mixed together. The water content of the mixture was maintained between $60-70 \%$, and the mixture was cultured at $28^{\circ} \mathrm{C}$ for $120 \mathrm{~d}$. All the treatments were triplicates. The samples were collected at $0,7,14,28,42,63$, and $120 \mathrm{~d}$. The collected samples were stored in $0-4^{\circ} \mathrm{C}$. The sterilized water was added each three days based on the weight balance.

Table 1. The Treatments During the Decomposition

\begin{tabular}{cll}
\hline Treatments & & \\
\hline A & 1 & Corncob + Soil solution (10\%) \\
(control & 2 & corncob + MU (10\%) \\
experiment) & 3 & corncob + MU (5\%) + Soil solution (5\%) \\
& 1 & corncob + Pyr + Soil solution (10\%) \\
B & 2 & corncob + Pyr + MU (10\%) \\
& 3 & corncob + Pyr + MU (5\%) + Soil solution (5\%)
\end{tabular}

Concentration of Pyr is $20 \mathrm{mg} / \mathrm{kg}$ dried corncob; Percentage of soil solution and MU is volume ratio in which MU means M. mucedo.

\subsection{Determination}

\subsubsection{Pyr extraction and analysis}

Extraction of pyrene was performed according to Yufang et al. [19]: $20 \mathrm{~mL}$ of dichloromethane and $3.0 \mathrm{~g}$ air-dried corncob were added to each corncob sample in the glass centrifuge tube, then, samples were extracted by sonication at $30-35^{\circ} \mathrm{C}$ for $2 \mathrm{~h}$. The extraction was repeated three times and the extracts were combined. The final extract was completely dried by evaporation of the dichloromethane under a stream of nitrogen. The residuals were dissolved in $2 \mathrm{~mL}$ filtered methanol and filtered through a $0.22-\mu \mathrm{m}$ hydrophobic syringe filter (Nantong Filterbio Membrane, China). The concentrations of PYR were determined by high performance liquid chromatography (Agilent 1200s) equipped with a fluorescence detector [20].

The wavelength for the fluorescence detector was $240 \mathrm{~nm}$. Separation was performed using a ZORBAX Eclipse C18 analytical column $(250 \times 4.6 \mathrm{~mm}$ id, $5 \mu \mathrm{m})$ with an operating temperature of $35^{\circ} \mathrm{C}$. The isocratic immobile-phase consisted of methanol and water $(90: 10 \mathrm{v} / \mathrm{v})$ at a flow rate of $0.7 \mu \mathrm{L} / \mathrm{m}$. The injection volume was fixed at $10 \mu \mathrm{L}$. The moisture was determined [by ISO 11465:1993] to allow data presented on a dry matter basis.

\subsubsection{E4/E6 ratio in dissolved organic matter of corncob}

The E4/E6 ratio is extensively used in soil science to indicate the humification degree (decomposition of organic matter); the 
progressive humification, which had the strong adsorption for pyrene due to the strengthened hydrophobic property, is indicated by a decreasing E4/E6 quotient [21]. The E4/E6 ratio was determined by dividing the absorbance at $465 \mathrm{~nm}$ (Abs465) by that at $665 \mathrm{~nm}$ (Abs665) for the individual samples [22]. dissolved organic matter (DOM) was obtained according to Long et al. [23]. 1.0 g sample was put into a centrifuge tube and $20 \mathrm{~mL}$ of ultrapure water was added and shaken for $4 \mathrm{~h}$ at $200 \mathrm{rad} / \mathrm{min}$. The supernatant was obtained after the mixture was centrifuged at 4,000 rpm for 10 min 4 h shock at $200 \mathrm{rad} / \mathrm{min}$. Then, the supernatant was filtrated through the 0.45 $\mu \mathrm{m}$ water membrane and stored in polypropylene bottles at $4^{\circ} \mathrm{C}$ prior to analysis. The obtained DOM was measured at the wavelength of 465 $\mathrm{nm}$ and $665 \mathrm{~nm}$ by UV-765 spectrophotometer. If the color of leach liquor was too deep and was beyond reading range of the spectrophotometer, before determination, the leach liquor needed to be diluted with ultrapure water several times before determination at first.

\subsubsection{Population structure changes of soil microorganisms}

Population structure of soil microorganisms was analyzed by polymerase chain reaction - denaturing gradient gel electrophoresis (PCR-DGGE) method. PCR-DGGE technique is a common method for the analysis of microbial population structure in microbial ecology, which has been widely used at present. Given laboratory conditions, PCR-DGGE technique was used to determine changes of microbial community structure and microbial diversity.

PCR-DGGE in present study was carried out according to the study of Su et al. [24]. The corncob samples (0.1 g wet weight) were used for DNA extraction with the TaKaRa MiniBEST Bacteria Genomic DNA Extraction Kit Ver. 3.0. The primer pair GC-954F / 1369R was used to obtain DNA fragments 496 bp in length. All PCR was performed with a PTC-200 thermal cycler (MJ Research Inc., USA). The PCR products then were verified by running a $1.2 \%(\mathrm{w} / \mathrm{v})$ agarose gel electrophoresis. DGGE was carried out using a DCode Universal Mutation Detection System (Bio-Rad, USA). The PCR-DGGE banding pattern was analyzed by Quantity-One image analysis software (Bio-Rad, USA) and Shannon index $(\mathrm{H})$, Shannon evenness (E) and Simpson dominance (D) were calculated according to the following equations.

$$
\begin{gathered}
H=\sum_{i=1}^{s} P_{i} \ln \left(P_{i}\right) \\
E=H / \ln S \\
1 / D=1-H=\sum_{i=1}^{s} P_{i}^{2}
\end{gathered}
$$

Where $P_{i}$ is the ratio of the gray scale of DGGE band $P_{i}$ to that of all bands in each lane; $S$ is the total number of DGGE bands.

\section{Results and Discussion}

\subsection{Pyr Degradation}

In group B where Pyr was added, the contents of extractable Pyr all decreased rapidly in the first 28 days and reached to a relatively low value in day 28 since the immobilizing carrier began to decompose (Fig. 1), after which they undergone rises and falls until the presence of the minimum in day 120. In initial decomposition stage, the decline rate of extractable Pyr in B2 was greater than that in B3 and B1. Content of extractable Pyr in B3 changed little during day 14 to day 63 , but after day 63 it decreased dramatically. After the troughs in day 28 in B1 and B2, the content of extractable Pyr in B1 and B2 rose first and then fell with the peak values in day 42 and day 63, respectively. The content of extractable Pyr in B2 where only MU was added was far lower than that inB1 and B3 (except in day 63). The content of extractable Pyr in B3 and in B1 had significant difference from $14 \mathrm{~d}$ to $42 \mathrm{~d}$. After 120 days decomposition, there was no significant difference in contents of extractable Pyr in B1, B2, and B3. As the decomposition deepening, the content of extractable Pyr in undecomposed parts decreased gradually. In addition, Pyr usually served as a carbon source for microorganisms, leading to the decomposition of Pyr and the decrease of extractable Pyr. However, the increase of pyrene concentration during the degradation process was probably because of the release rate of Pyr sequestrated by corncob during the degradation of Pyr [17].

Based on the degradation dynamics of the above five materials, the relation among the microbial population structure and the characteristics of the corncob during the decomposition of the corncob were studied. For instance, by analyzing the changes of microbial components of and humic substances during the decomposition of cow dung + straw, Chen et al. [25] found that inoculation with microorganism resulted in faster decomposition of organic fractions and more formation of humic substances which might affect the degradation of the PAHs [26]. Tang found that DOM from the rice straw enhanced the solubility of pyrene gradually in soil during the decomposition process because more and more hydrophobic sub-fractions were produced in soil organic matter (SOM) which could bind pyrene strongly [27]. The content and chemical composition of DOM undergone dynamic changes during the decomposition of rice straw [28]. Cheng found that DOM had an obvious solubilizing effect for PAH [29]. According to researches of Xiao, effects of DOM composition on Pyr adsorption

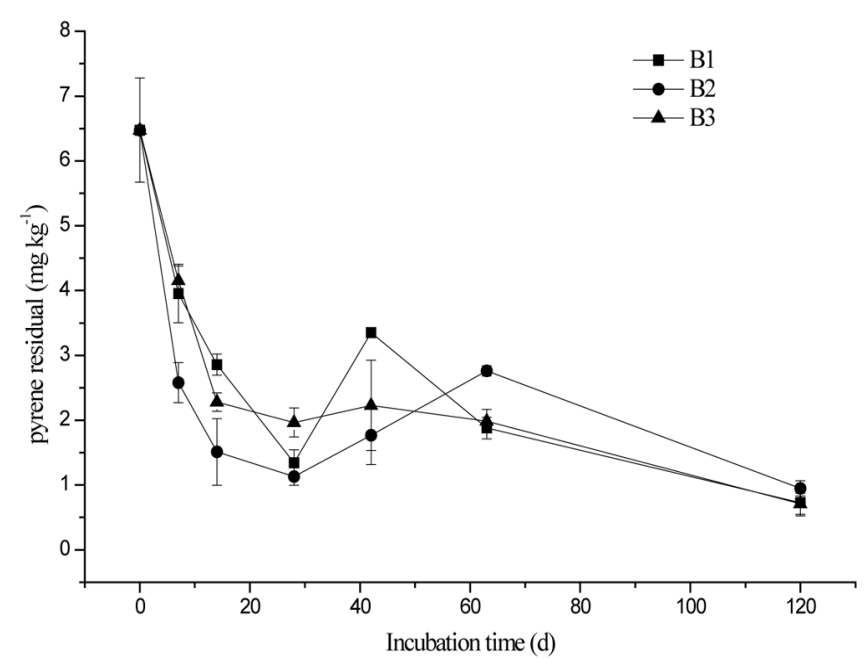

Fig. 1. The exactable Pyr in corncob during the decomposition process. 
were related to concentration of each component of DOM and in addition, the content of Pyr adsorbed by soil decreased with the increase of concentration of DOM components [30].

\subsection{E4/E6 Changes}

E4/E6 can describe the type and nature of Humic acid and reflect the condensation degree of aromatic ring in humic acid molecules, the aromatization degree and the molecular weight which are negatively correlated to the value of E4/E6. The values of E4/E6 are different for different sources (Fig. 2).

It can be seen from Fig. 2 that E4/E6 values changed greatly in 0-14 d and 63-120 d, while in 14-63 d the changes were relatively small. E4/E6 values in all groups declined obviously before day 14 and then generally leveled off, however they increased to some extent after day 63. The large gap among E4/E6 values of the treatments from 0 to $14 \mathrm{~d}$ was probably due to the high microbial activity and pyrene degradation during this period, in which the great amount of the secretions from microorganisms and various intermediate products of pyrene were produced being consistent with the degradation process of pyrene. Rising trend during 63-120 $\mathrm{d}$ was probably because of the emergence of new active microorganisms. E4/E6 values in A3 and B3 where soil solution was added were relatively low, indicating that rich microorganisms could promote aromatization and condensation of humus.

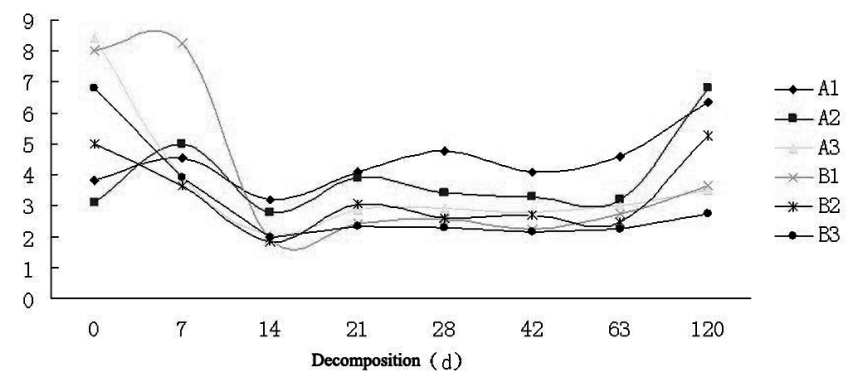

Fig. 2. Humic acid E4/E6 changes during decomposition process.

\subsection{Microbial Diversity Changes During Decomposition Process}

Microbial diversity not only represents stability of microbial community, but also reflects the effects of soil ecological mechanism and soil stress on community stability etc. from the other side. Researches and analysis of richness, evenness and other indexes of microorganisms were carried out to provide theoretical support and necessary experimental data. Diversity indexes such as Shannon index $(\mathrm{H})$, Shannon evenness $(\mathrm{E})$ and Simpson dominance (D) can not only reflect the characteristics of soil microbial community structure from different aspects, but also can be used to analyze differences in community types and structures and dynamic changes of community succession.

As can be seen from table 2, there was no Pyr added in soil solution in A1 and A3 treatments. The bacterial diversity index (H) decreased, which showed that bacterial population number decreased continuously with the continuous consumption of nutrients. Pyr was added in soil solution in B1 and B3 treatments.
Table 2. Shannon diversity index $(\mathrm{H})$ of soil solution of different treatment at different time

\begin{tabular}{cccccc}
\hline Treatments/Days & $\mathbf{3 ~ d}$ & $\mathbf{7 ~ d}$ & $\mathbf{1 4} \mathbf{d}$ & $\mathbf{2 8} \mathbf{d}$ & $\mathbf{4 2} \mathbf{d}$ \\
\hline A1 & 1.51 & 1.41 & 1.34 & 1.22 & 1.12 \\
A3 & 1.62 & 1.82 & 1.26 & 1.38 & 1.42 \\
B1 & 1.40 & 1.61 & 1.25 & 1.02 & 1.84 \\
B3 & 1.38 & 1.31 & 1.20 & 1.10 & 1.68 \\
\hline
\end{tabular}

Table 3. Shannon evenness index (E) of soil solution of different treatment at different time

\begin{tabular}{cccccc}
\hline Treatments/Days & $\mathbf{3 ~ d}$ & $\mathbf{7 ~ d}$ & $\mathbf{1 4} \mathbf{~ d}$ & $\mathbf{2 8} \mathbf{d}$ & $\mathbf{4 2} \mathbf{d}$ \\
\hline A1 & 0.77 & 0.80 & 0.81 & 0.80 & 0.79 \\
A3 & 0.76 & 0.78 & 0.79 & 0.78 & 0.80 \\
B1 & 0.78 & 0.79 & 0.77 & 0.78 & 0.80 \\
B3 & 0.82 & 0.81 & 0.78 & 0.79 & 0.82 \\
\hline
\end{tabular}

Table 4. Simpson dominance (D) of soil solution of different treatment at different time

\begin{tabular}{cccccc}
\hline Treatments/Days & 3 d & $\mathbf{7 ~ d}$ & $\mathbf{1 4} \mathbf{~ d}$ & $\mathbf{2 8} \mathbf{~ d}$ & $\mathbf{4 2} \mathbf{d}$ \\
\hline A1 & 1.41 & 1.48 & 1.50 & 3.06 & 1.76 \\
A3 & 1.46 & 1.38 & 1.36 & 2.78 & 1.51 \\
B1 & 1.58 & 1.42 & 1.61 & 1.86 & 1.48 \\
B3 & 1.52 & 1.51 & 1.53 & 1.68 & 1.64 \\
\hline
\end{tabular}

"There was no soil solution in T2 and T5, so fungi DNA was not found.

The bacterial diversity index $(\mathrm{H})$ experienced a rising trend after the first reduction, which showed Some vulnerable bacteria was inhibited in early decomposition, while the population number increased, because Pyr provided carbon source for the later decomposition. Comparison of B1 and B3 adding MU, bacterial diversity index $(\mathrm{H})$ was lower than that without added. The reason was competition of carbon source. which was similar to the result that Mucor separate treatment of the decomposition was better than the other treatment. As can be seen from table 3, Shannon evenness index (E) of all treatments varied little, its $E$ value was between 0.77-0.82. As can be seen from table 4, Simpson dominance (D) of all treatments increased continuously, and reached a maximum value in the $28 \mathrm{~d}$. So Pyr adding MU decomposition had greater impact to microbial species in soil, while had little impact to Shannon evenness (E) and Simpson dominance (D) of bacteria.

\section{Conclusions}

1) As the decomposition proceeded, the content of extractable Pyr decreased rapidly and then undergone rises and falls until the presence of the minimum in day 120 . However, the increase in pollutant concentration during the decomposition process was probably because the release rate of Pyr adsorbed by corncob was faster than the degradation rate of Pyr.

2) Treatment where only MU was added was more effective than other treatments in PAHs degradation especially in earlier period. In addition, Pyr-degrading bacteria also existed in indigenous microorganisms, which significantly reduced the content 
of Pyr in corncob. Adding both MU and soil microorganisms didn’t significantly improve the efficiency of Pyr degradation, probably due to the competition between MU and soil microorganisms for carbon and nitrogen and the low concentration of MM (5\%) compared to the only MU treatment.

3) Microbial life activities and superposition of various intermediate products in decomposition process probably resulted in the large gap among E4/E6 values in different treatments. E4/E6 values in two treatments where soil solution was added were relatively low, indicating that rich microorganisms could promote aromatization and condensation of humus.

4) Pyr adding MU decomposition had greater impact to microbial species in soil, while had little impact to Shannon evenness (E) and Simpson dominance (D) of bacteria.

\section{Acknowledgments}

This research is supported by NSFC (Natural Science Foundation of China (41101295, 31100349, 41201310 and 41271336) and by China Scholarship Council.

\section{References}

1. Bouchard DC, Wood AL, Campbell ML, Nkedi-Kizza P, Rao PS. Sorption nonequilibrium during solute transport. J. contam. Hydrol. 1998;2:209-223.

2. Fismes J, Perrin-Ganier C, Empereur-Bissonnet P, Morel JL. Soil-to-root transfer and translocation of polycyclic aromatic hydrocarbons by vegetables grown on industrial contaminated soils. J. Environ. Qual. 2002;31:1649-1656.

3. Gan S, Lau EV, Ng HK. Remediation of soils contaminated with polycyclic aromatic hydrocarbons (PAHs). J. Hazard. Mater. 2009;172:532-549.

4. Teng Y, Luo Y, Sun M, Liu Z, Li Z, Christie P. Effect of bioaugmentation by Paracoccus sp strain HPD-2 on the soil microbial community and removal of polycyclic aromatic hydrocarbons from an aged contaminated soil. Bioresour. Technol. 2010;101:3437-3443.

5. Murray MR, Hall JK. Sorption-desorption of dicamba and 3, 6-dichlorosalicylic acid in soils. J. Environ. Qual. 1989;18:51-57.

6. Li P, Li H, Stagnitti F, et al. Biodegradation of pyrene and phenanthrene in soil using immobilized fungi Fusarium sp. Bull. Environ. Contam. Toxicol. 2005;75:443-450.

7. Su D, Li PJ, Xin W. Immobilization of combined bacteria and its degradation of pyrene and benzo[a]pyrene in contaminated soil. J. Liaoning Technical Univ. 2007;26:461-463.

8. Wang X, Li PJ, Song S, Verkhozina VA. Degradation of polycyclic aromatic hydrocarbons in soils by Immobilized Microorganism. J. Northeastern Univ. 2006;27:1154-1156.

9. Li P, Wang X, Stagnitti F, et al. Degradation of phenanthrene and pyrene in soil slurry reactors with immobilized bacteria Zoogloea sp. Environ. Eng. Sci. 2005;22:390-395.

10. Gentili AR, Cubitto MA, Ferrero MA, Rodriguéz MS. Bioremediation of crude oil polluted seawater by a hydrocarbon degrading bacterial strain immobilized on chitin and chitosan flakes. Int. Biodeterior. Biodegradation 2006;57:222-228.

11. Mohammadi A, Nasernejad B. Enzymatic degradation of anthracene by the white rot fungus Phanerochaete chrysosporium immobilized on sugarcane bagasse. J. Hazard. Mater. 2009;161: 534-537.

12. Su D, Li PJ, Stagnitti F, Xiong XZ. Biodegradation of benzo[a]pyrene in soil by Mucor sp. SF06 and Bacillus sp. SB02 co-immobilized on vermiculite. J. Environ. Sci. 2006;18: 1204-1209.

13. Dzul-puc JD, Esparza-garcia F, Barajas-aceves M, RodríguezVázquez R. Benzo[a]pyrene removal from soil by Phanerochaete chrysosporium grown on sugarcane bagasse and pine sawdust. Chemosphere 2005;58:1-7.

14. Li XJ. Study on environmental behavior of polycyclic aromatic hydrocarbons in soil aging sewage irrigation [dissertation]. Shenyang: China science Shenyang institute of applied ecology institute; 2007.

15. Covino S, Svobodová K, Čvančarová M, et al. Inoculum carrier and contaminant bioavailability affect fungal degradation performances of PAH-contaminated solid matrices from a wood preservation plant. Chemosphere 2010;79:855-864.

16. Covino S, Čvancarova M, Muzikar M, et al. An efficient PAH-degrading Lentinus (Panus) tigrinus strain: Effect of inoculum formulation and pollutant bioavailability in solid matrices. $J$. Hazard. Mater. 2010;183:669-676.

17. Li X, Li P, Lin X, Zhang C, Li Q, Gong ZQ. Biodegradation of aged polycyclic aromatic hydrocarbons (PAHs) by microbial consortia in soil and slurry phases. J. Hazard. Mater. 2008;150: 21-26.

18. Wang S, Li X, Liu W, et al. Degradation of pyrene by immobilized microorganisms in saline-alkaline soil. J. Environ. Sci. 2012;24: 1662-1669.

19. Yufang S, Ziqing O, Tieheng S, Yediler A, Lorinci G, Kettrup A. Analytical method of polycyclic aromatic hydrocarbons (PAHs) in soil and plant samples. Chinese J. Appl. Ecol. 1995;6:92-96.

20. Dong D, Li P, Li X, Zhao Q, Zhang Y, Jia C, Li P. Investigation on the photocatalytic degradation of pyrene on soil surfaces using nanometer anatase $\mathrm{TiO}_{2}$ under UV irradiation. J. Hazard. Mater. 2010;174:859-863.

21. Campitelli P, Ceppi S. Effects of composting technologies on the chemical and physicochemical properties of humic acids. Geoderma 2008;144:325-333.

22. Wallage ZE, Holden J, McDonald AT. Drain blocking: An effective treatment for reducing dissolved organic carbon loss and water discolouration in a drained peatland. Sci. Total Environ. 2006;367:811-821.

23. Long GQ, Jiang YJ, Sun B. Seasonal and inter-annual variation of leaching of dissolved organic carbon and nitrogen under long-term manure application in an acidic clay soil in subtropical China. Soil Till. Res. 2015;146:270-278.

24. Su Z, Wang J, Li X., Li X, Zhang H, Li P. The effect of polycyclic aromatic hydrocarbon contamination on distribution of the Sphingomonas community in the Shenfu irrigation area of Northeast China. Ann. Microbiol. 2013;63:1005-1012. 
25. Chen XN, Lai HX, Tian XH, Wang XD. Dynamics of organic fractions of cow manure plus wheat straw during decomposition with microbial inoculation. J. Agro-environ. Sci. 2009;28:2417-2421.

26. Marschner B, Winkler R, Jodemann D. Factors controlling the partitioning of pyrene to dissolved organic matter extracted from different soils. Eur. J. Soil Sci. 2005;56:299-306.

27. Tang D, Wu J, Chen H, Zhou J. Effect of dissolved organic matter on the sorption and desorption behavior of pyrene in soil. Acta scientiae circumstantiae 2010;30:814-819.
28. Tang DM. The dynamic change of dissolved organic matter and its effects on the sorption-desorption of organic pollutants [dissertation]. Sichuan: Sichuan agricultural Univ.; 2008.

29. Cheng KY, Lai KM, Wong JWC. Effects of pig manure compost and nonionic-surfactant Tween 80 on phenanthrene and pyrene removal from soil vegetated with Agropyron elongatum. Chemosphere 2008;73:791-797.

30. Xiao YJ. Fractionation of dissolved organic matter during the decaying process of rice straw and it environmental significance [dissertation]. Sichuan: Sichuan agricultural Univ.; 2009. 